\title{
Influence of Open Porosity, Hydration Products and Extent of Hydration on the Strength of Desilicated Lime Fly Ash Composites
}

\author{
Thabo FALAYI ${ }^{1,2}$, Felix Ndubisi OKONTA ${ }^{1}{ }^{*}$, Freeman NTULI $^{2}$ \\ ${ }^{1}$ Department of Civil Engineering Sciences, University of Johannesburg, P.O. Box 524, Auckland Park 2006, \\ Johannesburg, South Africa \\ ${ }^{2}$ Department of Chemical Engineering, University of Johannesburg, P.O. Box 17011, Doornfontein 2028, Johannesburg, \\ South Africa
}

cross $^{\text {ref }}$ http://dx.doi.org/10.5755/j01.ms.23.2.14915

Received 06 May 2016; accepted 17 October 2016

\begin{abstract}
The prediction of strength of lime ash composites is critical for quality control, material performance monitoring and material serviceability limit state. A study was conducted to investigate the influence of open porosity (an index of micro grain alignment and macro particle parking), sum of hydration products and extent of hydration of desilicated fly ash (DFA) on the unconfined compressive strength (UCS) of DFA lime composites. A comparison with as received fly ash (FA) was also done. The wet and dry cycle durability of DFA and as received FA composites was also investigated. The DFA and FA composites were found to have a UCS of 8.6 MPa and 7.9 MPa respectively. The FA composite was found to be more durable than the DFA composite as after 10 wet and dry cycles the composites had a UCS of 3.5 and $1.8 \mathrm{MPa}$ respectively. Statistical correlation between UCS and open porosity, extent of FA/DFA hydration and sum of hydration products was implemented by Multivariate analysis. For both FA and DFA it was observed that the three parameters combined (open porosity, extent of FA/DFA hydration and sum of hydration products) had the greatest influence on the UCS than individually. This study shows that no single parameter on its own can adequately be used to predict UCS of FA/DFA lime composites. Correlation coefficients above 0.98 were found to describe the relationship between the three parameters and UCS for each composite. Thus could account for differences in durability or soaked strength of materials with equal initial dry strength.

Keywords: multivariate analysis, hydration products, open porosity, desilicated fly ash.
\end{abstract}

\section{INTRODUCTION}

Unconfined compressive strength (UCS) of fly ash (FA) composites is affected by various physical parameters of the composite. These include porosity, content of hydration products and extent of hydration of FA. It has been established that porosity affects UCS of composites $[1,2]$. Porosity is defined as the volume proportion of voids of material. Total open porosity is difficult to measure due to close voids and trapped air in dead end pores. The disequilibrium theory states that any condition that hinders the flow of desorbed water to an open surface will increase likelihood of damage [3]. Invariably high porosity hinders the flow leading to reduced UCS and durability of composite and reduced durability of composite. Several empirical formulas have been postulated that relate UCS to porosity. $[4,5]$. The most common formulas are as follows:

$$
\begin{aligned}
& S=M_{1}\left(1-(1-P)^{1+\theta 1 c}\right)^{2 / 3} ; \\
& S=S_{0}(1-P)^{A} .
\end{aligned}
$$

where $S$ is the UCS, $M_{l}$ is a constant which represent the theoretical compressive strength of concrete with zero porosity, $c$ is the capillary coefficient, $\theta 1, \theta 2$ and $A$ are constants, and $P$ is porosity. All the formulas include a factor of a theoretical value of strength at zero porosity.

\footnotetext{
* Corresponding author. Tel.: +275592342.

E-mail address: fnokonta@uj.ac.za (F.N. Okonta)
}

Close voids and trapped air in dead end pores make it difficult to determine total open porosity, open porosity can be used. Open porosity, $f$, is defined as the voids volume in which the water can penetrate due to immersion. Porosity has successfully been used to predict frost resistance in concrete $[6,7]$. The correlation between UCS and hydration products is well established $[8,9]$. These hydration products have been shown to increase mechanical strength and reduce the permeability properties of composites. The relationship between UCS and hydration products alone has shown poor correlation giving $R^{2}$ value of 0.84 [10]. A quick survey on lime and FA hydration reaction shows that less than $40 \%$ FA takes part in hydration reaction [11-13]. Therefore, the extent of FA hydration will have a great influence on the porosity and the formation of hydration products in turn affecting the UCS of the FA composite. A survey of literature shows that there is no mathematical modelling, which shows the combined effects of porosity, hydration products and extent of ash hydration on UCS. The aim of this paper is to find the correlation between open porosity, sum of hydration products and extent of desilicated fly ash (DFA)/FA hydration with UCS. The paper also seeks to find out if the influence on UCS by these three parameters is on an individual basis or coupled or combined effects. In addition, the study seeks to provide explanation for the differences in durability (soaked strength) or moisture resistance of materials with equal dry strength. The study was done by varying the DFA/FA: lime ratio and each composite was tested for open porosity, sum of hydration 
products and extent of DFA/FA hydration. The model can be used to come up with combinations to reach maximum UCS. For the purposes of this study curing period and water content were kept constant. The durability of the optimum strength composite was also established using alternative wet and dry cycles.

\section{MATERIALS AND METHODS}

The as received FA was leached for silica using $\mathrm{KOH}$. The conditions were a leaching time of 6 hours, $3 \mathrm{M} \mathrm{KOH}$, $500 \mathrm{rpm}$ agitation speed, 25 liquid solid (L/S) ratio and a leaching temperature of $100{ }^{\circ} \mathrm{C}$ [14]. The leaching was done so as to produce potassium silicate solution which could be used for high-temperature welding with carbon arc electrodes, decorative coatings, paints, ceramic binders and as adsorbents in acid mine drainage treatment. Desilicated fly ash (DFA) was obtained through desilication of FA from the Camden power station in South Africa. Commercially available hydrated Lime was supplied by Home Builders.

Oven dry DFA and lime were dry mixed at ratios of 95:5, 90:10, 85:15, 80:20, 75:25 70:30, 65:35 and 60:40. Water was quantitatively added at $30 \%$ of the dry solids. For each mix ratio two moulds were prepared. The mixed DFA-lime-water mixture was cast into a $100 \times 100 \times 100 \mathrm{~mm}^{3}$ mould and pressure molded from one end using a moulding load of $5 \mathrm{kN}$. The moulding was done at maximum dry densities for each particular ratio of DFA: lime. When the mould had obtained sufficient strength it was demoulded and subsequently sealed in a plastic. Casts which showed uneven surfaces due to demoulding or pressure casting were rejected. The same procedure was repeated with FA.

The plastic sealed cast were cured for $96 \mathrm{~h}$ at $80^{\circ} \mathrm{C}$. After $96 \mathrm{~h}$ the cast were removed from the oven and allowed to cool to room temperature.

\subsection{Strength prediction}

For each pair of cured composites the following tests were carried out.

\subsubsection{UCS}

UCS is the maximum load per unit area a cylindrical specimen can withhold before failing. UCS was determined in accordance with ASTM D2166. UCS was done on the cast that had no visible signs of failure and dimensions had not changed by more than $10 \%$. UCS was measured using a UCS machine with a loading rate of $15 \mathrm{kN} / \mathrm{min}$. The results were an average of two casts within $10 \%$ of each other.

\subsubsection{Extent of DFA hydration}

The extent DFA hydration represent the percentage of DFA/FA which takes part in the hydration reactions with lime. A modified picric acid methanol method was used [11]. $1 \mathrm{~g}$ of DFA: lime composite was accurately weighed into a teflon beaker. A picric acid-methanol solution $(9 \mathrm{~g}: 60 \mathrm{ml})$ was added to the composite material. The mixture was stirred for $15 \mathrm{~min}$ and subsequently $40 \mathrm{ml}$ of deionised water was added and stirring was continued for another $45 \mathrm{~min}$. The mixture was immediately filtered using ashless filter paper. The ash-less filter paper and the residue were washed with methanol until the filtrate appeared colourless and they were further washed with $300 \mathrm{ml}$ of deionized water at $60^{\circ} \mathrm{C}$. The residue and ashless filter paper were ignited in an electric furnace at $950^{\circ} \mathrm{C}$ for $60 \mathrm{~min}$. The $\%$ reacted DFA was calculated using Eq. 3:

$$
Y=\left(1-\left(S / P_{f} F\right)\right) * 100,
$$

where $S$ is the residue per gram of the composite, $P_{f}$ is the $\%$ DFA in the composite, $F$ is the residue for pure DFA. The same procedure was repeated with FA.

\subsubsection{Open porosity}

A modified ASTM C373-14a was used to determine open porosity. Composites of DFA:Lime were cured at $80^{\circ} \mathrm{C}$ for $96 \mathrm{~h}$. After curing, their mass was recorded. The composites were soaked in water for $24 \mathrm{~h}$. $24 \mathrm{~h}$ had been determined as the time when an increase in mass of wet cast was less than $1 \%$. After $24 \mathrm{~h}$ the composites were removed from water and visible water on the composite was wiped using soft cloth. The wet composites were weighed within 5 min of being removed from water. Open porosity, $\mathrm{f}$, was calculated as

$$
f=W_{s}-W_{d} / V \alpha
$$

where $W s$ is the mass of the soaked composite, $W_{d}$ was the mass of the dry composite, $V$ was the volume of the composite and $\alpha$ was the density of water. The same procedure was repeated with FA.

\subsubsection{Sum of hydration product (SH)}

$\mathrm{SH}$ was the total percentage of hydration products in each composite as determined by XRD. The SH were found to be calcium silicate hydrate and tricalcium aluminate hydrate for DFA composite and calcium aluminate silicate hydrate and calcium silicate hydrate for FA composites.

\subsection{Statistical analysis}

A SigmaXL 6.0 workbook was used to perform multivariate analysis between UCS and porosity $(f)$, sum of hydration products $(\mathrm{SH})$ and extent of hydration of DFA (Ext).

\subsection{Linear shrinkage}

TMH 1 method A4 (South African standard) was used to determine linear shrinkage of the cured 70:30 DFA composite. This was also repeated with the 80:20 FA composite.

\subsection{Durability (wet and dry cycles)}

A modified ASTM D559 03 method was used. The cured 70:30 DFA:lime composite was subjected to alternating $24 \mathrm{~h}$ soak followed by $24 \mathrm{~h}$ drying at $71{ }^{\circ} \mathrm{C}$ (this constituting one cycle). A total of 10 cycles were performed on the composites. The above method was repeated for the 80:20 FA:lime composite. 


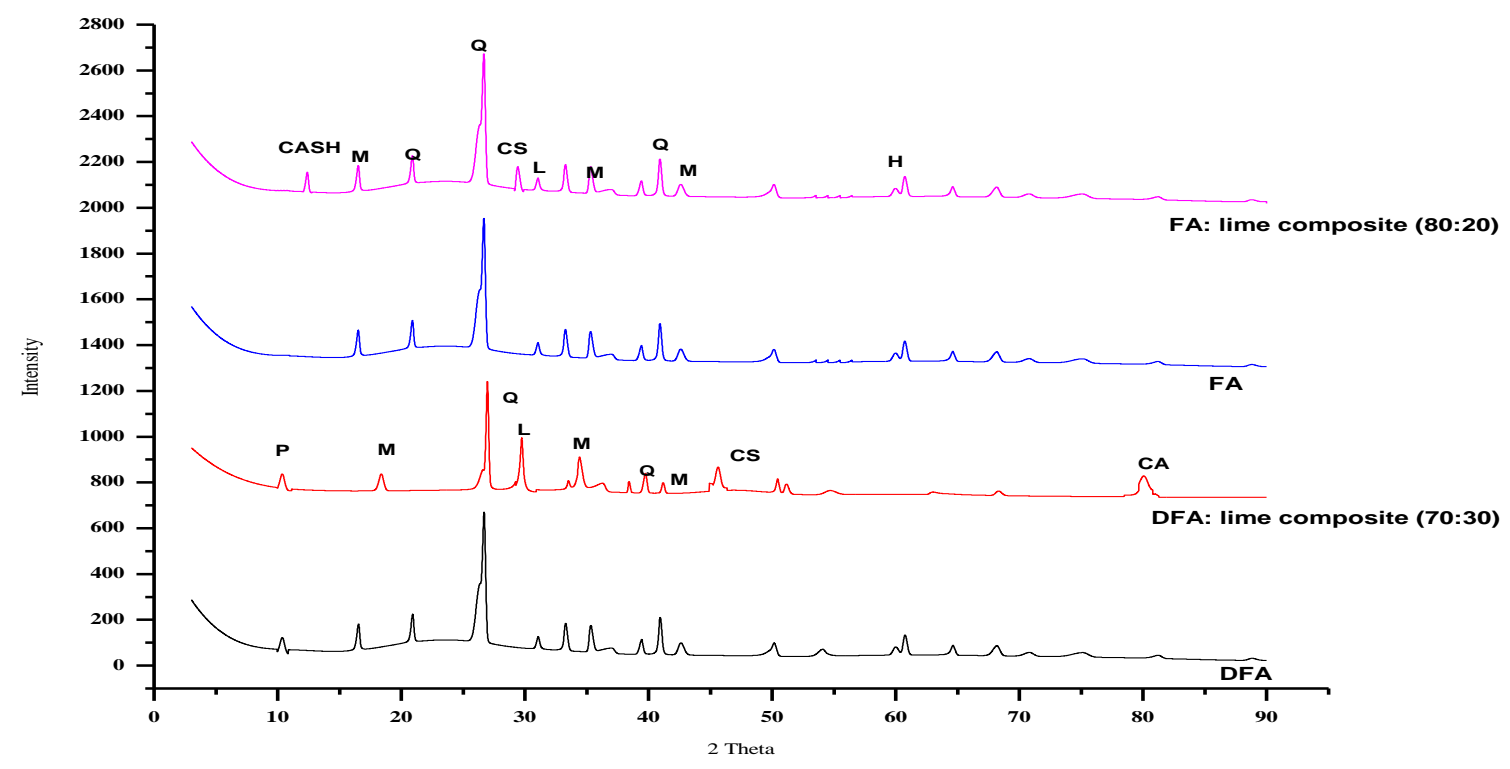

Fig. 1. XRD patterns of FA and DFA composites. P: Philipsite K, M: Mullite, Q: Quartz, L: CaO, CS: Calcium silicate hydrate, CA: tricalcium aluminate hydrate, $\mathrm{CASH}$ : Calcium aluminium silicate hydrate, $\mathrm{H}$ : Haematite

\section{RESULTS AND DISCUSSION}

\subsection{XRD analysis of DFA and FA lime composite}

Fig. 1 shows the DFA/FA and Lime composites XRD analysis. The major difference between DFA and FA is the presence of zeolite Philipsite $\mathrm{K}$ in DFA. The zeolite was formed during the silica leaching from FA. The hydration products of DFA are tricalcium aluminate and calcium silicate whilst the hydration products for FA were calcium silicate and calcium aluminium silicate hydrate. Zeolites are recognised as supplementary cementitious material in concrete and hence the higher strength of DFA paste [15] (Table 1 and Table 4).

Table 1. Variation in properties of DFA composites with lime content

\begin{tabular}{|c|c|c|c|c|}
\hline DFA: Lime & UCS, MPa & $f$ & SH & Ext \\
\hline $95: 5$ & 0.7 & 0.357 & 0.08 & 0.15 \\
\hline $95: 5$ & 0.8 & 0.385 & 0.08 & 0.15 \\
\hline $90: 10$ & 3.8 & 0.303 & 0.12 & 0.20 \\
\hline $90: 10$ & 3.9 & 0.301 & 0.13 & 0.23 \\
\hline $85: 15$ & 3.9 & 0.298 & 0.13 & 0.24 \\
\hline $85: 15$ & 4.0 & 0.295 & 0.14 & 0.24 \\
\hline $80: 20$ & 7.9 & 0.291 & 0.21 & 0.34 \\
\hline $80: 20$ & 7.7 & 0.281 & 0.21 & 0.36 \\
\hline $75: 25$ & 7.9 & 0.275 & 0.22 & 0.36 \\
\hline $75: 25$ & 8.1 & 0.275 & 0.25 & 0.34 \\
\hline $70: 30$ & 8.7 & 0.260 & 0.28 & 0.35 \\
\hline $70: 30$ & 9.2 & 0.240 & 0.29 & 0.36 \\
\hline $65: 35$ & 7.1 & 0.299 & 0.22 & 0.34 \\
\hline $65: 35$ & 7.2 & 0.302 & 0.22 & 0.36 \\
\hline $60: 40$ & 6.5 & 0.312 & 0.21 & 0.34 \\
\hline $60: 40$ & 6.4 & 0.319 & 0.21 & 0.34 \\
\hline
\end{tabular}

\subsection{Strength prediction using DFA}

Table 1 shows the variation of UCS with open porosity, sum of hydration products and DFA extent of hydration. There was an increase in UCS as the lime content increased from 5 to $30 \%$. The 70:30 DFA:lime composite was found to have the highest UCS and therefore was taken to be the optimum. There was a $24.4 \%$ drop in UCS for the 60:40 compared to the 70:30 DFA:lime combination. This can be explained by noting that lime was in excess at a ratio 60:40. Excess lime does not participate in hydration reactions thereby it ends up as weak filler which reduces the strength of the composite. The increase in UCS was also accompanied by a decrease in open porosity and an increase in the extent of DFA hydration and hydration products. There was a decrease in porosity as the lime content increased up to $30 \%$, this was also associated with the increase in UCS. This was mainly due to increase in contact as porosity decreased [16, 17]. The increase in porosity at 35 and $40 \%$ lime is due to less packing of the material.

There was an increase in the extent of DFA hydration with an increase in lime due to increase in available lime for hydration [12].

A multivariate analysis was conducted to evaluate the degree of the correlation between UCS and open porosity, sum of hydration products and extent of DFA hydration.

\subsubsection{Multivariate analysis}

Table 2 shows the multivariate analysis.

Table 2. Multivariate Analysis

\begin{tabular}{|l|l|}
\hline Correlation between & $\mathrm{R}^{2}$ value \\
\hline UCS and $f$ & 0.6974 \\
\hline UCS and $f$ and SH & 0.9484 \\
\hline UCS and $f$, SH and Ext & 0.9825 \\
\hline
\end{tabular}

From Table 2 it can be shown that there was a high correlation between UCS and the three other parameters combined. This therefore proves that the development of strength in DFA lime composite is highly dependent on the open porosity of the composite, the sum of hydration products and the extent of hydration of DFA. These results are significant in that it is for the first time that the 
combined effect of porosity, $\mathrm{SH}$ and extent of DFA reaction is presented giving us a better understanding on the effect of these parameters on UCS. The model for prediction of strength was found to be as follows,

$U C S=3.491-17.104 f+13.512 S H+16.90$ Ext.

Statistical analysis of the model showed the model was sound as Durbin-Watson statistic was found to be 1.8 which is close to 2 showing that the residuals were not auto-correlated. This was further proved by the normal probability plot of regular residuals. Fig. 2 shows the normal probability plot.

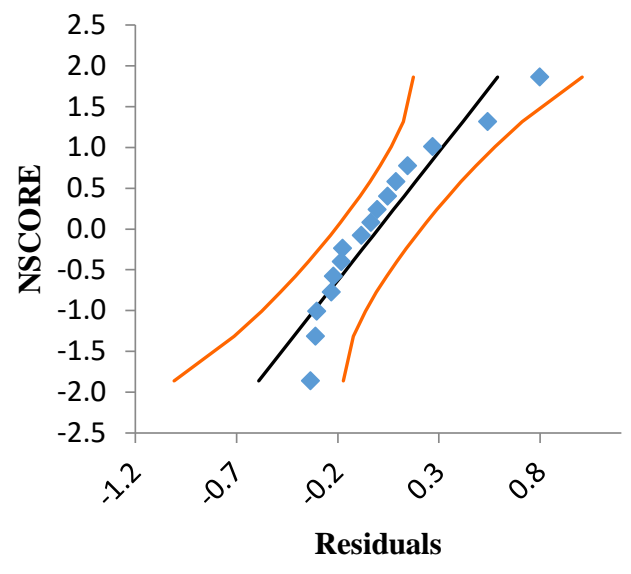

Fig. 2. Residuals normal probability plot

The residuals were centred on the mean showing no bias in the model.

\subsubsection{Linear shrinkage}

Linear shrinkage of samples that were prepared at the liquid limit were found to be $5.8 \%$. High shrinkage may cause excessive warpage and thereby may induce cracking which causes deleterious effect on structures. The linear shrinkage of the DFA composite was found to be within acceptable levels.

\subsubsection{Durability using wet and dry cycles}

Fig. 3 shows the variation in UCS with number of cycles of the DFA: lime composite (70:30).

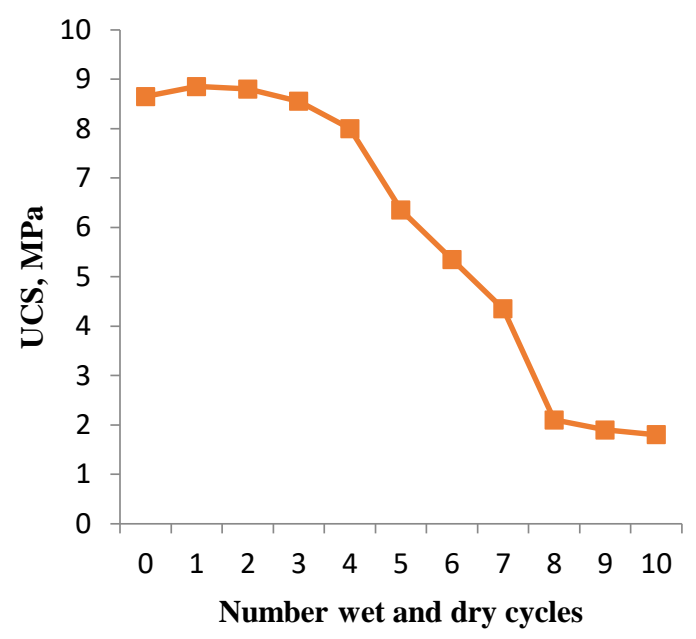

Fig. 3. Variation of UCS with number of cycles
After 1 cycle there was a gradual decrease in the UCS of the composite. After 8 cycles the composite failed as its UCS was below 3.5 which is the minimum UCS required by the South African Building council for non-facing plastered brick [16]. The decrease in UCS was also accompanied by the increase in open porosity of the composites, which was a result of water ingress during soaking. Table 3 shows the variation in porosity with the number of cycles. The 70:30 DFA: lime composite was taken as the optimum. Similar UCS, open porosity, extent of FA hydration trends to those of DFA were noticed.

Table 3. Variation in DFA porosity with number of cycles

\begin{tabular}{|c|c|}
\hline Cycle & Ave porosity \\
\hline 0 & 0.25 \\
\hline 1 & 0.24 \\
\hline 2 & 0.27 \\
\hline 3 & 0.27 \\
\hline 10 & 0.29 \\
\hline
\end{tabular}

\subsection{Strength prediction using FA}

Table 4 shows the variation of UCS with open porosity, sum of hydration products and FA extent of reaction. The increase in UCS was accompanied by decrease in porosity, increase in $\mathrm{SH}$ and extent of FA reaction $[12,16,17]$. A multivariate analysis was conducted to evaluate the degree of correlation between UCS and open porosity, sum of hydration products and extent of FA hydration. Table 5 shows the multivariate analysis

Table 4. Variation in properties of FA composites with lime content

\begin{tabular}{|c|c|c|c|c|}
\hline DFA: Lime & UCS, MPa & $\mathrm{f}$ & SH & Ext \\
\hline $95: 5$ & 0.5 & 0.361 & 0.1 & 0.16 \\
\hline $95: 5$ & 0.4 & 0.368 & 0.1 & 0.17 \\
\hline $90: 10$ & 2.8 & 0.348 & 0.13 & 0.28 \\
\hline $90: 10$ & 2.9 & 0.354 & 0.13 & 0.28 \\
\hline $85: 15$ & 3.8 & 0.313 & 0.24 & 0.29 \\
\hline $85: 15$ & 4.1 & 0.324 & 0.24 & 0.29 \\
\hline $80: 20$ & 7.9 & 0.301 & 0.33 & 0.38 \\
\hline $80: 20$ & 7.8 & 0.308 & 0.33 & 0.38 \\
\hline $75: 25$ & 6.4 & 0.314 & 0.28 & 0.38 \\
\hline $75: 25$ & 6.6 & 0.318 & 0.28 & 0.38 \\
\hline $70: 30$ & 6.2 & 0.329 & 0.27 & 0.32 \\
\hline $70: 30$ & 6.4 & 0.328 & 0.27 & 0.32 \\
\hline
\end{tabular}

Table 5. Multivariate analysis

\begin{tabular}{|l|l|}
\hline Correlation between & $\mathrm{R}^{2}$ value \\
\hline UCS and $f$ & 0.7752 \\
\hline UCS and $f$ and SH & 0.9196 \\
\hline UCS and $f$, SH and Ext & 0.9817 \\
\hline
\end{tabular}

From Table 5 it can be shown that there was a high correlation between UCS and the three other parameters combined. This validates that open porosity of the cast, the sum of hydration products and the extent of hydration of FA have a high impact on FA lime composites. The model for prediction of strength was found to be as follows,

$U C S=-25.082+54.247 f+28.284 S H+19.979 E x t$ 
Statistical analysis of the model showed the model was sound as Durbin-Watson statistic was found to be 2.3 which is close to 2 showing that the residuals were not auto-correlated. This was further proved by the normal probability plot of regular residuals. Fig. 4 shows the normal probability plot. The residuals were centred on the mean showing no bias in the model. This therefore means the UCS prediction model is sound.

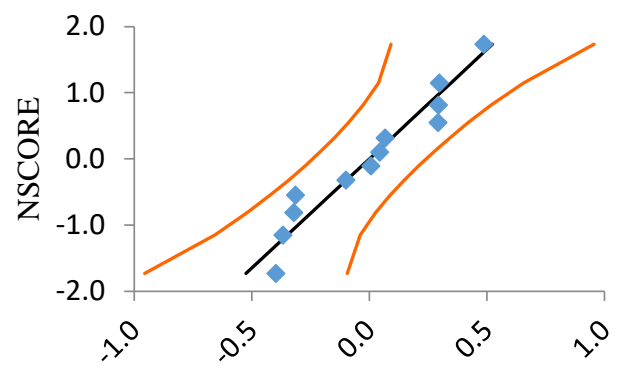

Residuals

Fig. 4. Residuals normal probability plot

\subsubsection{Linear shrinkage}

Linear shrinkage of samples that were prepared at the liquid limit was found to be $6.2 \%$. The linear shrinkage of the FA composite was found to be within acceptable levels.

\subsubsection{Durability using wet and dry cycles}

Fig. 5 shows the variation in UCS with number of cycles FA: lime composite (80:20).

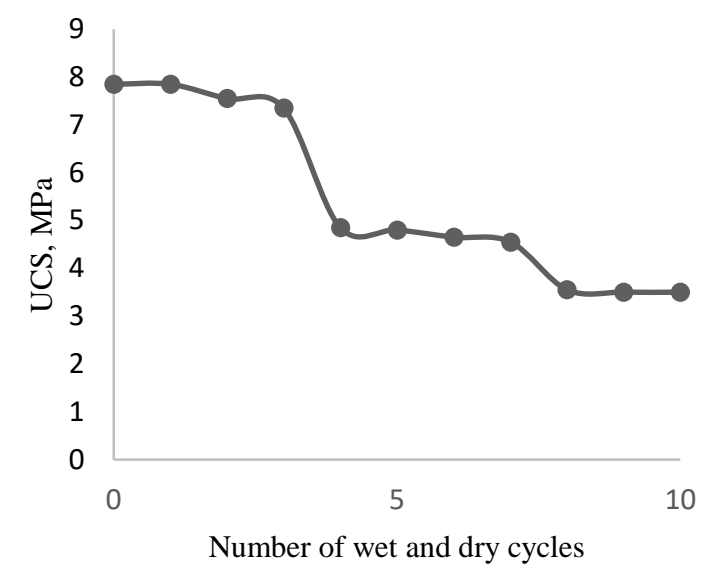

Fig. 5. Variation of UCS with number of cycles

There was a $34 \%$ drop in UCS after the fourth cycle. Although 4 cycles of rainfall and dry weather in some part of the world may be considered extreme, extreme weather patterns are common in most tropical and semi-arid regions and thus design criterion for the use of the materials in tropical environment must take cognizance of the observed reduction in strength. After 10 cycles the UCS of the composite was found to be $3.5 \mathrm{MPa}$. Although this value was within requirements for UCS for non-facing bricks using the South African Burnt masonry standard [16], the major deduction is the likelihood of significant strength reduction from long term exposure to moisture. Table 6 shows the variation in porosity with the number of cycles for FA lime composite.

The gradual decrease in UCS (Fig. 5) was accompanied with the gradual increase in porosity as the number of cycles increased.

Table 6. Variation in FA composite porosity with number of cycles

\begin{tabular}{|c|c|}
\hline Cycle & Ave porosity \\
\hline 0 & 0.30 \\
\hline 1 & 0.29 \\
\hline 2 & 0.29 \\
\hline 3 & 0.29 \\
\hline 10 & 0.34 \\
\hline
\end{tabular}

\section{CONCLUSIONS}

The 70:30 DFA: lime composite had a UCS of 8.6 MPa whereas the 80:20 FA: lime composite had a UCS of $7.9 \mathrm{MPa}$. Both composites showed that there was an increase in UCS with an increase in extent of DFA/FA hydration, sum of hydration products and decrease in open porosity. The UCS of both composites was influenced by the combined effects of open porosity, sum of hydration products and extent of DFA/FA hydration. A correlation coefficient of above 0.98 was found for both composite together with a Durbin-Watson statistic close to 2 showing that the residuals were not autocorrected. This showed the models were sound. The decrease in UCS with increase in wet and dry cycles for both composite was accompanied with increase in open porosity. FA lime composites were more durable than the DFA composite due to more available silica to taking part in hydration reaction in FA. It is common practice in composite material analysis to relate strength development to either porosity or hydration products only. The results however indicate that process component (extent of DFA/FA hydration and sum of hydration products) and structure (open porosity) are critical for strength prediction, as well as provide the micro mechanical basis for the difference in durability or soaked strength of materials with equal dry strength.

\section{Acknowledgements}

The results presented in this document are part of the doctoral thesis of Mr Thabo Falayi. The authors would like to thank the University Research Council of the University of Johannesburg for their financial support. The authors are also thankful to the National Research Foundation of South Africa for providing a bursary for the student.

\section{REFERENCES}

1. Wang, J.C. Young's Modulus of Porous Materials: Part 2. Young's Modulus of Porous Alumina with Changing Pore Structures Journal of Materials Science 19 1984: pp. 809-814.

2. Phani, K.K., Niyogi, S.K. Young Modulus of Porous Brittle Solids Journal of Materials Science 22 1987: pp. $257-63$.

3. Mensinga, P. Determining the Critical Degree of Saturation of Brick Using Frost Dilatometry. Master of Applied 
Science in Civil Engineering Waterloo, Ontario, Canada, 2009.

4. Akyüz, S., Tasdemir, M.A., Uyan, M. Pore Effects on the Compressive Strength of Concrete Proceedings of the International Conference on Concrete 2000: Economic and Durable Construction Through Excellence 2000: pp. $1408-1416$.

5. Uchikawa, H., Okanura, T. Binary and Ternary Components Blended Cement. ABI Books, New Delhi, 1993: pp. 1-83.

6. Nagrockienė, D., Skripkiūnas, G., Girskas, G. Predicting Frost Resistance of Concrete with Different Coarse Aggregate Concentration by Porosity Parameters Materials Science (Medžiagotyra) 17 2011: pp. 203-207.

7. Kulovaná, ., Pokorný, J., Keppert, M., Pavlík, Z., Cerný, R. Strength Development and Physical Properties of Cement Paste with Incorporated Ceramic Powder Materials Science (Medžiagotyra) 22 2016: pp. 82-87.

8. Rao, S.M., Asha, K. Activation of Fly Ash-Lime Reactions: Kinetic Approach Journal of Materials in Civil Engineering 24 2012: pp. 1110-1117. https://doi.org/10.1061/(ASCE)MT.1943-5533.0000482

9. Prashanth, J.P., Sivapullaiah, P.V., Sridharan, A. Pozzolanic Fly Ash as a Hydraulic Barrier in Landfills Engineering Geology 61 2001: pp. 245-252.

10. Khoury, N.N., Zaman, M., Laguros, J.G. Use of XRD Patterns to Evaluate Compressive Strength of Stabilized Aggregates International Centre for Diffraction Data 2004 Advances in X-ray Analysis 47 2004: pp. 379-384.
11. Zhang, Y.M., Sun, W., Yan, H.D. Hydration of highvolume fly ash cement pastes Cement and Concrete Composites 22 2000: pp. 445-452. https://doi.org/10.1016/S0958-9465(00)00044-5

12. Haha, M.B., De Weerdt, K., $\quad$ Lothenbach, $B$. Quantification of the Degree of Reaction of Fly Ash Cement and Concrete Research 40 2010: pp. 1620-1629. https://doi.org/10.1016/j.cemconres.2010.07.004

13. Nugteren, H.W. Secondary Industrial Minerals from Coal Fly Ash and Aluminium Anodising Waste Solutions. PhD thesis, Delft University of Technology, 2011.

14. Falayi, T., Ntuli, F., Okonta, F.N. Kinetic and Thermodynamic Parameters of Silica Leaching from Camden Power Station Fly Ash Proccedings of the $4^{\text {th }}$ International conference on Energy systems, environment, entrepreneurship and innovation (ICESEEI) 2015: pp. $241-248$.

15. Vaičiukynienè, D., Vaitkevičius, V., Kantautas, A., Kartovickis, A., Rudžionis, Z. Blended Cements Produced with Synthetic Zeolite Made from Industrial By-Product Materials Science (Medžiagotyra) 21 2015: pp. 136-142.

16. Consoli, N.C., Foppa, D., Festugato, L., Heineck, K.S. Key Parameters for Strength Control of Artificially Cemented Soils Journal of Geotechnical and Geoenvironmental Engineering 133 2007: pp. 197-205. https://doi.org/10.1061/(ASCE)1090-0241(2007)133:2(197)

17. Consoli, N.C., Rotta, G.V., Prietto, P.D.M. Yielding Compressibility-Strength Relationship for an Artificially Cemented Soil Cured Under Stress Geotechnique 56 2006: pp. 69-72.

18. SANS 227:2007: Burnt clay masonry units. 